\title{
Objectives and methodology of Romanian SEPHAR II Survey. Project for comparing the prevalence and control of cardiovascular risk factors in two East-European countries: Romania and Poland
}

\author{
Maria Dorobantuㄹ, Oana-Florentina Tautuㄹ, Roxana Darabont ${ }^{2}$, Silviu Ghiorghe ${ }^{3}$, Elisabeta Badila ${ }^{3}$, \\ Minca Dana ${ }^{4}$, Minodora Dobreanu ${ }^{5}$, Ilarie Baila ${ }^{6}$, Marcin Rutkowski ${ }^{7}$, Tomasz Zdrojewski ${ }^{7}$
}

\author{
${ }^{1}$ Cardiology Department, Clinical Emergency Hospital Bucharest, \\ University of Medicine and Pharmacy "Carol Davila", Bucharest, Romania \\ ${ }^{2}$ Cardiology Department, University Emergency Hospital Bucharest, University \\ of Medicine and Pharmacy "Carol Davila", Bucharest, Romania \\ "Internal Medicine Department, Clinical Emergency Hospital Bucharest, \\ University of Medicine and Pharmacy "Carol Davila”, Bucharest, Romania \\ ${ }^{4}$ Public Health National Institute, Bucharest, Romania \\ ${ }^{5}$ Clinical Biochemistry Department, University of Medicine and Pharmacy, \\ Târgu Mureş, Romania \\ ${ }^{6}$ SynLab Romania, Bucharest, Romania \\ ${ }^{7}$ Department of Hypertension and Diabetology, Medical University of Gdansk, \\ Gdansk, Poland
}

Submitted: 10 March 2014

Accepted: 11 July 2014

Arch Med Sci 2015; 11, 4: 715-723

DOI: 10.5114/aoms.2015.53290

Copyright (c) 2015 Termedia \& Banach

\section{Abstract}

Introduction: Comparing results of representative surveys conducted in different East-European countries could contribute to a better understanding and management of cardiovascular risk factors, offering grounds for the development of health policies addressing the special needs of this high cardiovascular risk region of Europe. The aim of this paper was to describe the methodology on which the comparison between the Romanian survey SEPHAR II and the Polish survey NATPOL 2011 results is based.

Material and methods: SEPHAR II, like NATPOL 2011, is a cross-sectional survey conducted on a representative sample of the adult Romanian population (18 to 80 years) and encompasses two visits with the following components: completing the study questionnaire, blood pressure and anthropometric measurements, and collection of blood and urine samples.

Results: From a total of 2223 subjects found at 2860 visited addresses, 2044 subjects gave written consent but only 1975 subjects had eligible data for the analysis, accounting for a response rate of $69.06 \%$. Additionally we excluded 11 subjects who were 80 years of age (NATPOL 2011 included adult subjects up to 79 years). Therefore, the sample size included in the statistical analysis is 1964. It has similar age groups and gender structure as the Romanian population aged 18-79 years from the last census available at the moment of conducting the survey (weight adjustments for epidemiological analyses range from 0.48 to 8.7 ).

Conclusions: Sharing many similarities, the results of SEPHAR II and NATPOL 2011 surveys can be compared by a proper statistical method offering crucial information regarding cardiovascular risk factors in a high-cardiovascular risk European region.

Key words: cross-sectional study, hypertension, metabolic disorders, cardiovascular disease, epidemiology.

\author{
Corresponding author: \\ Roxana Darabont MD, PhD \\ Cardiology Department \\ University Emergency \\ Hospital Bucharest \\ University of Medicine \\ and Pharmacy "Carol \\ Davila" Bucharest \\ Splaiul Independentei, \\ no. 169 \\ 050098 Bucharest, Romania \\ Phone: +40723441315 \\ E-mail: rdarabont@yahoo.com
}




\section{Introduction}

Each year cardiovascular disease (CVD) causes over 4.3 million deaths in Europe and over 2 million deaths in the European Union [1]. Cardiovascular disease is the main cause of death in women in all countries of Europe and is the main cause of death in men in all countries except France, the Netherlands, and Spain [1]. Death rates from CVD are generally higher in Central and Eastern Europe than in Northern, Southern and Western Europe $[1,2]$.

Cardiovascular disease is strongly connected to hypertension, metabolic disorders, and lifestyle, especially the use of tobacco, unhealthy dietary habits, physical inactivity, and psychosocial stress $[3,4]$. The World Health Organization (WHO) has stated that over three-quarters of all CVD mortality may be prevented with adequate changes in lifestyle [5].

Cardiovascular disease prevention, remaining a major challenge for the general population, politicians, and healthcare workers alike, is defined as a coordinated set of actions, at the public and individual level, aimed at eradicating, eliminating, or minimizing the impact of CVDs and their related disability [6]. The bases of prevention are rooted in cardiovascular epidemiology and evidence-based medicine [6].

Identifying individuals at high risk of developing CVD but who are currently asymptomatic is one of the main goals of primary prevention. Interventions targeted at modifiable risk factors, such as arterial hypertension (HT), hypercholesterolemia, obesity or smoking, can delay or even prevent the occurrence of CVD [7-10].

The lack of representative data for Romania's entire population regarding cardiovascular risk factors' prevalence led to the initiation of the SEPHAR (abbreviation of the full title: Study for the Evaluation of Prevalence of Hypertension and cArdiovascular Risk in Romania) project [11]. Consequently, in 2005 the first epidemiological study based on a representative sample for the entire adult population of Romania, SEPHAR I, was carried out. Its results confirmed Romania as a high cardiovascular risk country [12-15]. Between October 2011 and March 2012 a second epidemiological study, SEPHAR II, was carried out aiming for a more accurate estimation of prevalence of CV risk factors among Romania's adult population and their evolutionary trend during 2005-2012. Alongside hypertension (AHT), other CV risk factors studied in SEPHAR II are diabetes mellitus (DM), hypercholesterolemia, smoking and sedentary lifestyle [16-18].

Apart from the primary objective of SEPHAR II, namely to present the current epidemiologic situation regarding arterial hypertension and main CV risk factors among Romania's adult population and their evolution during the last 7 years (by comparison with SEPHAR I survey results), this survey was intended for comparison with the results of the Polish NATPOL 2011 survey, which could contribute to a better understanding and management of arterial hypertension and other CV risk factors in East-European countries, offering grounds for the development of health policies addressing the special needs of this high cardiovascular risk region of Europe.

This paper aims to describe the basis on which the comparison between SEPHAR II and NATPOL 2011 results was based on: the similarity of the two survey methodologies and the statistical procedures that allow the comparison between the two different populations with different structure.

The objectives and methodology of the NATPOL 2011 survey have been published elsewhere [19] and will be further discussed only in comparison with SEPHAR II. Below the methodology of the SEPHAR II survey is presented.

\section{Material and methods}

The SEPHAR II survey was conducted under the auspices of the Romanian Ministry of Health and the Romanian Society of Hypertension.

The key party responsible for project design and implementation was the team designated by the Romanian Society of Hypertension (SRH) and by the Cardiology Department of the Emergency Clinical Hospital of Bucharest. This team has previously participated in the design development and implementation of the first epidemiological study based on a representative sample of the entire Romanian adult population - SEPHAR I.

The study protocol and its implementation procedures were supervised by the project reviewers and approved by the Local Ethics Committee. Project reviewers were designated by the National Institute of Public Health, by the $2^{\text {nd }}$ Mathematics Department of the Faculty for Applied Science from the University of Bucharest, by the Biochemistry Department of the University of Medicine and Pharmacy Targu-Mures and by the Cardiology Department of the University of Medicine and Pharmacy Craiova.

\section{Research population}

For a research population of 16833541 Romanian adults of whom $40.1 \%$ are estimated to be hypertensive based on SEPHAR I results [7-9], with a maximum error of $\pm 2.18 \%$ at a confidence level of $95 \%$, the minimum required sample size is 1942 individuals.

\section{Sampling procedure}

Sampling was performed by a multi-stratified procedure, leading to the selection of a represen- 
tative sample of 1942 adults. Subject selection followed the principle of equality of chances of being enrolled in the study, regardless of the size of the place of residency (Figure 1).

Stratification criteria for sample selection were: - territorial regions (Romania's territory was divided into 7 regions plus the capital city Bucharest, based on the National Statistics Institute recommendations: the North-East region, the SouthEast region, the South region, the South-West region, the West region, the North-West region, the Central region and the Bucharest region);

- locality type (cities with over 200000 inhabitants, cities with 50 000-200 000 inhabitants, cities with less than 50000 inhabitants, Commune);

- gender (male and female);

- age groups (18-24 years, 25-34 years, 35-44 years, $45-54$ years, $55-64$ years, $65-80$ years).

In the first stage of selection, the adult population weighted average was calculated for each region and each district, and, based on this, the number of adult persons from each region/district was calculated from the working sample of 1942 subjects.

In the second stage of selection, the number of localities of a certain size from which the subjects were later selected was established for each district. This number was directly proportional to the population in the respective district. A random selection of a certain locality in a certain category was done using a computer software (generation of random numbers). The selected localities represent the interview centers where the study was to take place. The weighted average of the specific locality population in the district was calculated, and, based on this, the number of people selected to participate in the study.
The third stage of selection consisted of distribution by gender of adult people selected from each locality, using Romania's population gender distribution according to the 2002 census ( $F: M=$ $51.25 \%$ vs. $48.75 \%$ ) and the fourth stage of selection consisted of distribution by age of male and female adult people selected from each locality, using Romania's population age distribution according to the 2002 census.

\section{Interviewing address selection}

As the response rate was estimated to be lower than $50 \%$ in some regions, the number of addresses necessary for the study was calculated as double the number of selected people from each region. However, Bucharest was considered atypical from a statistical point of view and, thus, the number of addresses necessary for the study was calculated as three times the number of selected persons (Table I). Interviewing addresses were selected from the database of the Romanian Population General Direction of Data Records, where the streets are presented in alphabetical order.

Subject selection was done by choosing from this list the person written at the number corresponding to the selection STEP. This is calculated using the formula STEP $=N / n$, where $N$ is the number of people from the specific locality, and $n$ is the number of people selected in the research population sample of the respective locality. The starting point on the list designates the first subject selected, and is calculated using the formula STARTING POINT = STEP $/ 2$. The following subjects were selected from this point forward with a selection STEP calculated using the formula mentioned above.

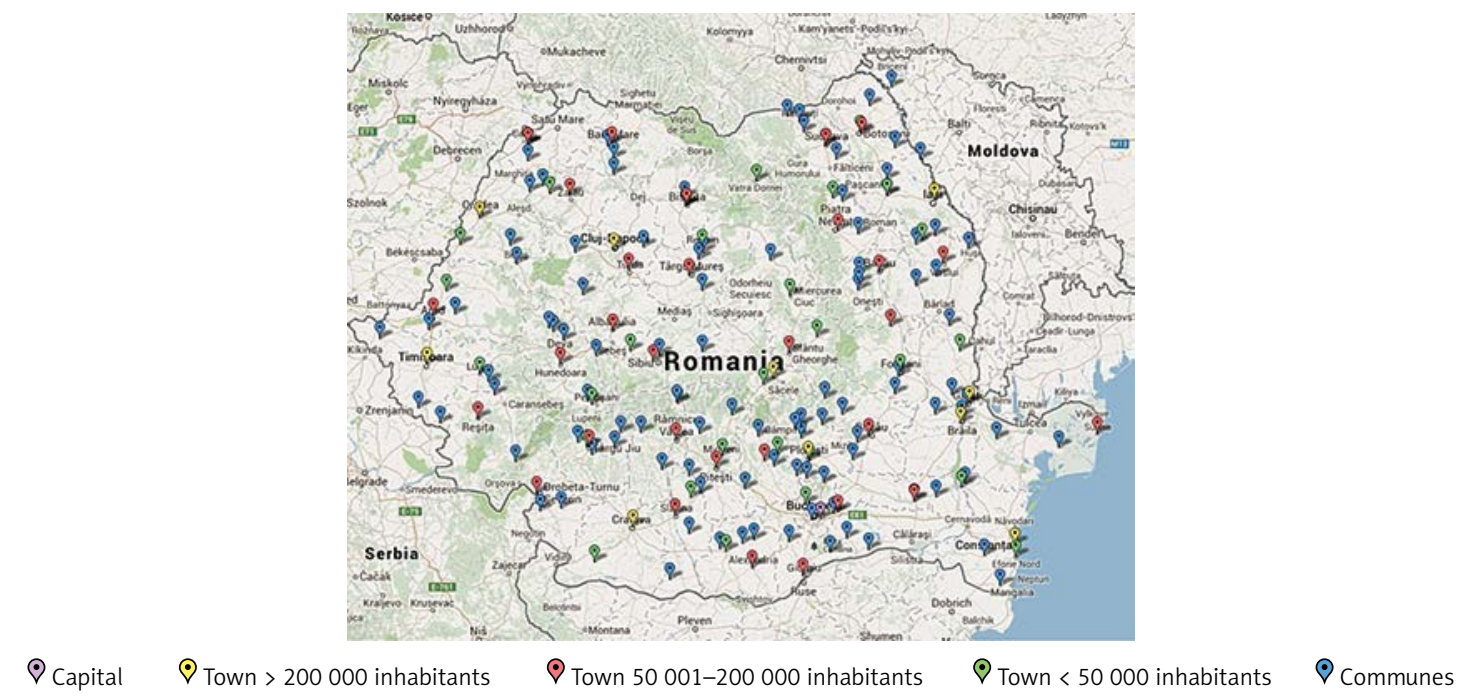

Figure 1. Distribution of SEPHAR II study sites 
Table I. Minimum required sample size and number of selected interview addresses

\begin{tabular}{|lccc|}
\hline Region & Minimum required sample & Number of selected addresses & Number of visited addresses \\
\hline North-East & 317 & 634 & 461 \\
\hline South-East & 255 & 510 & 270 \\
\hline South & 304 & 608 & 457 \\
\hline South-West & 209 & 418 & 390 \\
\hline West & 177 & 354 & 265 \\
\hline North-West & 244 & 488 & 397 \\
\hline Center & 226 & 452 & 330 \\
\hline Bucharest & 210 & 630 & 290 \\
\hline Total & 1942 & 4094 & 2860 \\
\hline
\end{tabular}

\section{Estimated statistical error}

This type of error originates in the fact that the study is carried out on a representative population sample and not on the entire population. The magnitude of this error depends on the size of the sample and on the value of the parameter to be estimated.

For a certain parameter expressed as a percentage value for a population sample of $n=1942$ subjects, the estimated statistical errors are between $\pm 1.13 \%$ and $\pm 2.19 \%$.

\section{Description of project implementation}

The survey encompasses two visits and its organizational stages are depicted in Figure 2.

Prior to actual fieldwork, all individuals selected through the sampling procedure received letters providing information regarding the project and its objectives and of the future visit by the study field physician.

The fieldwork team was composed of general practitioners (GPs) chosen by the members of the coordinating team from the regions selected upon sampling and responsible for subjects' enrollment, study questionnaire completion and

Letter of information sent to the selected addresses

Training sessions for fieldwork teams (GPs and nurses)

Visits at the selected addresses for subject enrollment

Data collection: questionnaires, laboratory analysis results

Figure 2. Structure of SEPHAR II survey's organizational stages blood pressure and anthropometric measurements, and a series of nurses designated by the laboratory coordinator, responsible for collection of blood and urine samples and their transport to the central laboratory.

\section{Team training}

Physicians who participated in the study were trained by the study implementation team before the start of fieldwork. In particular, training addressed the following issues: interviewer working principles, how to use the address lists, how to fill in the study questionnaire and how to take anthropometric and blood pressure measurements.

The nurses participating in the study were also trained by the central laboratory, regarding collection and transport of biological material samples.

\section{Fieldwork}

Each of the primary care physicians participating in the study received a list of addresses of individuals to be interviewed.

During the first visit, the GPs: briefly presented the objectives of the study, obtained written consent concerning participation in the study, filled in the study questionnaire, took anthropometric measurements (body weight, body height, waist and arm circumference), and carried out 3 blood pressure measurements. At the end of the visit he/she scheduled the time and date of the second study visit, and provided the patient with a urine container for the urine sample and with written instructions for urine collection and blood sample taking. During the second visit, the GPs performed a new series of 3 blood pressure measurements, 12-lead electrocardiogram and arterial stiffness measurements and the nurse designated by the central laboratory took blood and urine samples. 


\section{Data collection}

\section{Study questionnaire}

The study questionnaire consisted of 76 items: 7 items regarding socio-demographic data, 19 items regarding medical history (including past medical history and family history) and risk factors (smoking, leisure time, physical activity, etc.), 10 items regarding clinical symptoms, 4 items addressing socioeconomic barriers in accessing medical services, 16 items about the knowledge of methods of CVD prevention and complications due to poor control of risk factors, the source of knowledge about health and disease as well as usage of preventive methods, 12 items for sleep disorders and sleep apnea, 3 items regarding medication and 4 items specially addressed to females (females' medical history, use of birth-control pills).

The final part of the questionnaire included 10 items to be completed with the results of anthropometric and BP measurements and the details of blood and urine sample collection (5 items for each of the 2 study visits).

\section{Blood pressure measurements}

Blood pressure (BP) measurements were taken using an automatic oscillometric blood pressure measuring device certified by AAMI (Association for the Advancement of Medical Instrumentation), European Society of Hypertension (ESH) and the British Hypertension Society (BHS), model A\&D UA 95 Plus. The use of other devices was forbidden. Before performing BP measurements, arm circumference was measured (using a tailor's tape measure with a maximum deviation of $0.5 \mathrm{~cm}$, at the widest level of the arm) in order to choose the right cuff type (if the arm circumference was more than $32 \mathrm{~cm}$, a cuff for obese people was used, and if the arm circumference was equal to or less than $32 \mathrm{~cm}$, a standard cuff was used).

The GP took one BP measurement at both arms and after that took two additional measurements at the arm with the highest BP value on the first measurement, at time intervals of at least $1 \mathrm{~min}$.

Blood pressure measuring conditions respected the recommendations of the European Society of Hypertension. Thirty minutes before BP measurements the patient was not allowed to smoke, drink coffee or do exercise. Blood pressure measurements and thus the questionnaire were not applied to subjects under the obvious influence of alcohol consumption. In this situation, the physician scheduled a new meeting with the subject.

\section{Anthropometric measurements}

The anthropometric measurements were made using the following devices:
- weight - using an approved electronic scale (model Tanita HD 95), with a maximum deviation of $0.1 \mathrm{~kg}$, with the subject wearing light clothes (without outer garments and without shoes),

- height - using a portable measuring device with a maximum deviation of $0.5 \mathrm{~cm}$,

- waist circumference, hip circumference and arm circumference - using a tailor's measuring tool, with a maximum deviation of $0.5 \mathrm{~cm}$.

\section{Collection of blood samples}

Blood samples were collected at the investigator GP's office or at the subject's home if he/ she was not able to walk. Prior to taking a blood sample, the nurse made sure that the subject had not eaten for the past 8-14 h or that he/she had not drunk any sweet drinks or drinks of any caloric value in the past 8-14 h. The nurse used a preassembled blood draw kit containing a 22G needle, a vacutainer kit, $8 \mathrm{ml}$ vacuum type tube with separator gel for biochemistry, a $2 \mathrm{ml}$ vacuum type tube with EDTA anticoagulant for glycated hemoglobin and a $6 \mathrm{ml}$ vacuum type tube with sodium fluoride glycolytic inhibitor for blood glucose.

The nurse performed the following actions: confirmed the subject's personal data, took samples of venous blood with the subject in a sitting position with a maximum duration of stasis of $30 \mathrm{~s}$, transferred urine from the receptacle it was collected in by the subject to the vacuum transport tube, filled out the referral form to the laboratory (filling in the time and date of sample collection), marked all the test tubes with stickers containing the subject's individual study code, prepared the material for transportation and transported the material to the central laboratory.

\section{Central laboratory}

Laboratory testing was carried out after the materials were delivered to the central laboratory. The list of blood and urine tests is presented in Table II.

The test results were electronically delivered to the study organizers, who entered them in the database.

\section{Delivering patient results and procedure in case of significant abnormalities}

Each individual tested in the study received from their field GP written information regarding their blood pressure values. If diagnosed with arterial hypertension, the patient was informed that they would have to report to their primary care physician. If very high BP values were detected, carrying a high risk for acute complications (above $210 / 130 \mathrm{~mm} \mathrm{Hg}$ ), the patient was referred to an emergency care center. 
Table II. Laboratory work-up in SEPHAR II

\begin{tabular}{|c|c|c|c|c|c|c|c|c|}
\hline \multirow[t]{3}{*}{ Test } & \multirow[t]{3}{*}{$\begin{array}{l}\text { Methodology/reagents/ } \\
\text { manufacturer }\end{array}$} & \multirow[t]{3}{*}{ Analyzer } & \multicolumn{6}{|c|}{$\begin{array}{l}\text { Analytical characteristics } \\
\text { of the method applied }\end{array}$} \\
\hline & & & \multicolumn{2}{|c|}{ Bias } & \multicolumn{2}{|c|}{$\begin{array}{l}\text { Within-run } \\
\text { imprecision }\end{array}$} & \multicolumn{2}{|c|}{$\begin{array}{l}\text { Between-run } \\
\text { imprecision }\end{array}$} \\
\hline & & & $N$ & $P$ & $N$ & $P$ & $N$ & $P$ \\
\hline $\begin{array}{l}\text { Serum } \\
\text { creatinine }\end{array}$ & $\begin{array}{l}\text { Jaffe method/picric acid in alkaline } \\
\text { milieu/Roche }\end{array}$ & Cobas 6000 & -1.82 & -6.09 & 1.08 & 1.49 & 2.3 & 1.61 \\
\hline eGFR & \multicolumn{8}{|c|}{$\begin{array}{c}\text { Calculated using the simplified MDRD equation: eGFR }=175 \times\left[(S \times 0.0113)^{-1.154}\right] \times[\text { age }(\text { years })]^{-0.203} \times Z \\
\text { where: } S-\text { serum creatinine }[\mu \mathrm{mol} / /] ; Z=0.742 \text { (for females) and } 1 \text { (for males) }\end{array}$} \\
\hline $\begin{array}{l}\text { Serum uric } \\
\text { acid }\end{array}$ & $\begin{array}{l}\text { Enzymatic/uricase, peroxidase/ } \\
\text { Roche }\end{array}$ & Cobas 6000 & 0 & -2 & 0.9 & 0.7 & 2.2 & 2.2 \\
\hline $\begin{array}{l}\text { Serum } \\
\text { potassium }\end{array}$ & $\begin{array}{l}\text { ISE/indirect ion-selective electrode/ } \\
\text { Roche }\end{array}$ & Cobas 6000 & 0.7 & 0.7 & 0.5 & 0.5 & 0.75 & 0.92 \\
\hline $\begin{array}{l}\text { Serum } \\
\text { triglycerides }\end{array}$ & $\begin{array}{l}\text { Enzymatic/glycerol kinase and } \\
\text { glycerol phosphatase/Roche }\end{array}$ & Cobas 6000 & -4.17 & -3.81 & 1.12 & 0.69 & 2.1 & 2.3 \\
\hline $\begin{array}{l}\text { Serum total } \\
\text { cholesterol }\end{array}$ & $\begin{array}{l}\text { Enzymatic/cholesterol esterase and } \\
\text { cholesterol oxidase/Roche }\end{array}$ & Cobas 6000 & -0.36 & 0.36 & 0.65 & 1.18 & 1.79 & 1.84 \\
\hline $\begin{array}{l}\text { Serum HDL- } \\
\text { cholesterol }\end{array}$ & $\begin{array}{l}\text { Enzymatic/peg-cholesterol oxidase/ } \\
\text { Roche }\end{array}$ & Cobas 6000 & -3.11 & -4.14 & 1.23 & 0.9 & 2.05 & 3.16 \\
\hline $\begin{array}{l}\text { Serum LDL- } \\
\text { cholesterol }\end{array}$ & \multicolumn{8}{|c|}{$\begin{array}{l}\text { Using Friedewald formula: LDL-C }[\mathrm{mg} / \mathrm{dl}]=\text { total cholesterol }[\mathrm{mg} / \mathrm{dl}]-\mathrm{HDL}-\mathrm{C}[\mathrm{mg} / \mathrm{dl}]-\text { triglycerides } \\
{[\mathrm{mg} / \mathrm{dl}] / 5 \text {. If triglyceride concentration }>350 \mathrm{mg} / \mathrm{dl} \text {, Friedewald formula cannot be used }}\end{array}$} \\
\hline $\begin{array}{l}\text { Plasma } \\
\text { glucose }\end{array}$ & $\begin{array}{l}\text { Enzymatica/hexokinase } \\
\text { and glucose-6-phosphate } \\
\text { dehydrogenase/Roche }\end{array}$ & Cobas 6000 & -0.68 & -2.89 & 1.16 & 0.99 & 1.68 & 1.5 \\
\hline $\begin{array}{l}\text { Glycated } \\
\text { hemoglobin } \\
\left(\mathrm{HbA}_{1 \mathrm{c}}\right)\end{array}$ & $\begin{array}{l}\text { Tinia, IFCC standardised and DCC/ } \\
\text { NGSP traceable/Roche }\end{array}$ & Cobas 6000 & -3.74 & -8.14 & 1.5 & 1.1 & 1.34 & 2.06 \\
\hline Albuminuria & Immunoturbidimetry/Roche & Cobas 6000 & 0.93 & -2.3 & 2.5 & 2.19 & 2.5 & 1.1 \\
\hline
\end{tabular}

Laboratory results were communicated to individuals by mail, with a proviso that they would be completed with a delay of up to 6 weeks after actual collection of samples. A physician assessed results outside the normal range; if he considered that the respective result required diagnostic evaluation or emergency therapy (e.g. significant hypokalemia), the patient was informed of this fact by telephone, along with sending their results by mail.

People with fasting glucose $\geq 126 \mathrm{mg} / \mathrm{dl}$ were additionally referred for a fasting plasma glucose test in the local laboratory; those with blood glucose of 100-125 mg/dl received additional referral for a 75 g glucose oral tolerance test.

\section{Statistical analysis}

Statistical analysis was performed with IBM SPSS Statistics 20.0 software at a significance level of $p \leq 0.05$.

A descriptive analysis (means, medians, standard deviation and range for continuous data and frequency analysis for categorical data) was performed for all the target variables.

The Kolmogorov-Smirnov test was used to analyze continuous data distribution, according to which appropriate tests were further used in the analysis: independent samples $t$-test or Mann-Whitney $U$ test for differences between means of 2 independent groups, ANOVA or Kruskal-Wallis test for differences between means of 3 independent groups. The $\chi^{2}$ test was used to analyze differences between categorical data.

Data were weighted for region, locality type, age groups, and gender. Also, to account for differences between the two different populations (Romanian and Polish), Romanian data were weighted using the structure of the Polish adult population as a reference.

\section{Results}

\section{Response rate}

The study investigators approaching a total of 2223 subjects visited a total number of 2860 addresses from 182 study sites. From the 2044 subjects who gave written consent to participate in the study (179 refusals), at the end of the study only 1975 subjects had eligible data for the analysis (complete questionnaires + both study visits). Therefore the response rate of our study was $69.06 \%$. 


\section{Study flow}

From the total of 2044 subjects who gave written informed consent to participate in the study, 69 were excluded as follows: 36 subjects were lost to follow-up (LFU), 28 subjects with protocol violation (age above 80 years), 3 subjects with protocol violation and LFU and 3 subjects without case-report forms returned.

In order to compare results of SEPHAR II (a survey that included adults up to 80 years of age) with results of NATPOL 2011 (a survey that included adult subjects up to 79 years of age) we further excluded 11 subjects who were 80 years of age. Therefore, the total number of subjects included in the statistical analysis for comparison with Polish survey results was 1964, a number that satisfies the minimum sample size of 1942 subjects required for a representative sample of Romania's adult population.

\section{General characteristics of study group}

The actual participants in the study were those who signed a written informed consent for all elements of the study, i.e. the questionnaire, blood pressure and anthropometric measurements and laboratory work-up.

Among the participants, there were 1031 females and 933 males; 722 were aged $18-39$ years, 828 were aged $40-59$ years and 414 were aged 60-79 years. The mean age in the examined sample was $48.49 \pm 16.06$ years in females and 45.27 \pm 14.14 years in males.

As shown in Table III, the sample structure by age and gender is almost identical to the structure of the Romanian adult population from the last population census available at the time of conducting the survey; therefore the weighting adjustments calculated for epidemiological analyses were from 0.48 to 8.7 .

The socio-demographic characteristics of the study group are shown in Table IV.

\section{Discussion}

Like the Polish survey, implementation of the SEPHAR II study complied with the ethical and legal requirements imposed by Romanian law, good clinical practice rules and by the local ethics committee.

The interviewing addresses were selected from the database of the Romanian Population General Direction of Data Records in such a manner in which we did not reach a person with a precise identity but only a person with certain demographic characteristics (male or female of a certain age from a certain locality), respecting Law number $677 / 2001$ for the protection of individuals with regard to processing of personal data and the free movement of such data. Each subject was assigned a unique study code to ensure confidentiality of personal data collected during the survey. The questionnaire, urine, and blood samples from a specific subject had the aforementioned study code. Before enrollment, each subject gave written informed consent. The study protocol was approved by the local ethics committee.

As previously described in the methods section, SEPHAR II's protocol is similar to the NATPOL 2011 protocol in terms of having been conducted on representative samples of the Romanian adult population, of the age range of included subjects and of data collection and diagnostic algorithms used. Furthermore, both blood pressure measurements and anthropometric measurements from SEPHAR II and NATPOL 2011 surveys were performed with exactly the same devices, which were borrowed from the Polish team.

Adjusting the SEPHAR II results using the structure of the Polish adult population as a reference, direct comparison will be safely performed addressing the questions on how different the two populations are in terms of prevalence of main CV risk factors, such as arterial hypertension, dyslipidemia, smoking, or obesity.

In conclusion, sharing many similarities with the NATPOL 2011 survey, in terms of being conducted on a representative sample for the population aged 18 to 79 years, of data collection and diagnostic algorithms, the SEPHAR II survey results can be compared by a proper statistical method to the results from NATPOL 2011, offering up-to-date crucial information regarding arterial hypertension prevalence and control as well as prevalence of other CV risk factors in two high-cardiovascular risk East-European coun-

Table III. Structure of examined sample compared to structure of adult Romanian population according to last population census (LPC) available in 2011

\begin{tabular}{|lcccccc|}
\hline \multirow{2}{*}{ Age range [years] } & \multicolumn{2}{c}{ Females (\%) } & \multicolumn{2}{c}{ Males (\%) } & \multicolumn{2}{c|}{ Total (\%) } \\
\cline { 2 - 7 } & SEPHAR II & LPC & SEPHAR II & LPC & SEPHAR II & LPC \\
\hline $18-39$ & 35.1 & 41.6 & 38.6 & 45.5 & 36.8 & 43.6 \\
\hline $40-59$ & 38.5 & 33.3 & 46.2 & 33.7 & 42.2 & 33.5 \\
\hline $60-79$ & 26.4 & 25.1 & 15.2 & 20.6 & 21.1 & 22.9 \\
\hline
\end{tabular}


Table IV. Socio-demographic characteristics of study group

\begin{tabular}{|lcccccc|}
\hline Characteristics & \multicolumn{2}{c}{ Females } & \multicolumn{2}{c}{ Males } & \multicolumn{2}{c|}{ Total } \\
\cline { 2 - 7 } & $\boldsymbol{N}$ & $\%$ & $\boldsymbol{N}$ & $\%$ & $\boldsymbol{N}$ & $\%$ \\
\hline Education: & & & & & & \\
\hline Primary or uncompleted primary & 236 & 22.9 & 121 & 13 & 357 & 18.2 \\
\hline Uncompleted secondary & 94 & 9.1 & 58 & 6.2 & 152 & 7.7 \\
\hline Secondary or uncompleted higher & 486 & 47.1 & 502 & 53.8 & 988 & 50.3 \\
\hline Higher & 212 & 99.7 & 251 & 26.9 & 463 & 23.6 \\
\hline Missing data & 3 & 0.3 & 1 & 0.1 & 4 & 0.2 \\
\hline Place of residence: & & & & & & \\
\hline City > 200,000 residents & 261 & 25.3 & 217 & 23.3 & 478 & 24.3 \\
\hline Town 50,000-200,000 residents & 232 & 22.5 & 206 & 22.1 & 438 & 22.3 \\
\hline Town < 50,000 residents & 155 & 15 & 135 & 14.5 & 290 & 14.8 \\
\hline Rural areas & 383 & 37.1 & 375 & 40.2 & 758 & 38.6 \\
\hline Professional status: & 16 & 1.6 & 16 & 1.7 & 32 & 1.6 \\
\hline Employed/economic activity & 474 & 46 & 545 & 58.4 & 1019 & 51.9 \\
\hline Farmer & 54 & 5.2 & 44 & 4.7 & 98 & 5 \\
\hline Retired & 338 & 32.8 & 203 & 21.8 & 541 & 27.5 \\
\hline Unemployed with social support & 19 & 1.8 & 22 & 2.4 & 41 & 2.1 \\
\hline Unemployed without social support & 94 & 9.1 & 94 & 10.1 & 188 & 9.6 \\
\hline Not working/student & 36 & 3.5 & 9 & 1 & 45 & 2.3 \\
\hline Missing data & & & & & & \\
\hline
\end{tabular}

tries. These data may offer grounds for preventive strategies addressing the special needs of this region.

\section{Acknowledgments}

The authors express their gratitude to those who contributed to the SEPHAR II study: Dr. Tomasz Zdrojewski from Poland, for support regarding methodology development and for logistic support, Servier Pharma Romania, for financial and logistic support during the whole study duration, Clar Research, for the support regarding sampling, data management and statistical analysis of the data, and last but not least to all the general practitioners, nurses and residents who have been involved in this study.

This study was carried out with financial support from the Romanian Society of Hypertension and from SERVIER PHARMA - Romanian Branch.

\section{Conflict of interest}

The authors declare no conflict of interest.

\section{References}

1. European Cardiovascular Disease Statistics 2012. Available from: http://www.ehnheart.org/cvd-statistics.html

2. Bielecka-Dabrowa A, Aronow WS, Rysz J, Banach M. The rise and fall of hypertension: lessons learned from Eastern Europe. Curr Cardiovasc Risk Rep 2011; 5: 174-9.

3. Krzysztoszek J, Wierzejska E, Paczkowska A, Ratajczak P. Health-related behaviours and hypertension prevention in Poland. An environmental study. Arch Med Sci 2013; 9: 218-29.

4. Stępień M, Wlazeł RN, Paradowski M, et al. Serum concentrations of adiponectin, leptin, resistin, ghrelin and insulin and their association with obesity indices in obese normo- and hypertensive patients - pilot study. Arch Med Sci 2012; 8: 431-6.

5. World Health Organization. Cardiovascular Diseases: Fact Sheet No. 317. Geneva, Switzerland: WHO 2007.

6. A dictionary of epidemiology. 4th ed. Last MJ (ed.). Oxford University Press, New York 2001.

7. Mathers CD, Lopez AD, Stein D, et al. Deaths and disease burden by cause: Global Burden of disease estimates for 2001 by the World Bank Country Groups. Disease Control Priorities Working Paper: April 204, revised 2005.

8. Banach M, Serban C, Aronow WS, et al. Lipid, blood pressure and kidney update 2013. Int Urol Nephro 2014; 46: 947-61. 
9. Athyros VG, Katsiki N, Tziomalos K, et al. Statins and cardiovascular outcomes in elderly and younger patients with coronary artery disease: a post hoc analysis of the GREACE study. Arch Med Sci 2013; 9: 418-26.

10. Michalska M, Rysz J, Pencina MJ, Zdrojewski T, Banach $M$. The knowledge and awareness of hypertension among patients with hypertension in Central Poland: a pilot registry. Angiology 2014; 65: 525-32.

11. Dorobantu M, Tautu O. Romanian projects on cardiovascular risk factors research. Medicina Interna 2012; IX suppl 2012: 7-14.

12. Dorobantu M, Darabonț RO, Badila E, et al. SEPHAR study. Study for evaluation of prevalence of hypertension and cardiovascular risk in adult population in Romania. Part I: methodology. Romanian Heart J 2006; XXI; 2: 89-96.

13. Dorobanțu M, Darabonț RO, Bădilă E, et al. SEPHAR study. Study for evaluation of prevalence of hypertension and cardiovascular risk in adult population in Romania - Part II: results. Romanian Heart J 2006; XXI: 179-90.

14. Dorobanțu M, Darabonț RO, Bădilă E, et al. Prevalence, awareness, treatment, and control of hypertension in Romania: results of the SEPHAR Study. Int J Hypertens 2010; 2010: 970694.

15. Dorobantu M, Badila E, Ghiorghe S. Total cardiovascular risk estimation in Romania. Data from SEPHAR Study. Rom J Intern Med 2008; 46: 29-37.

16. Dorobantu M, Darabont R, Ghiorghe S, et al. Hypertension prevalence and control in Romania at a seven-year interval. Comparison of SEPHAR I and II surveys. J Hypertens 2014; 32: 39-47.

17. Dorobantu M, Darabont R, Ghiorghe S, et al. Profile of the Romanian hypertensive patient. Data from SEPHAR II study. Rom J Intern Med 2012; 50: 285-96.

18. Dorobantu M, Bartos D, Apetrei E, et al. Hypertension in Romania: where are we and what we do? Results from SEPHAR II study. Rom J Cardiol 2012; 22: 285-92.

19. Zdrojewski T, Rutkowski M, Bandosz P, et al. Prevalence and control of cardiovascular risk factors in Poland. Assumptions and objectives of the NATPOL 2011 Survey. Kardiol Pol 2013; 71: 381-92. 